\title{
A Gestão Integrada e o Estudo de Impacto Ambiental como Contribuição para o Parque Estadual Marinho de Areia Vermelha, Paraíba, Brasil ${ }^{1}$
}

\author{
http://dx.doi.org/10.21527/2237-6453.2020.51.230-246
}

Recebido em: 29/5/2019

Aceito em: $4 / 12 / 2019$

Thiago Araújo da Silva, ${ }^{2}$ Eduardo Rodrigues Viana de Lima ${ }^{3}$

\begin{abstract}
RESUMO
O Parque Estadual Marinho de Areia Vermelha - Pemav - é uma das unidades de conservação paraibanas com os mais desafiadores aspectos de gestão e monitoramento das atividades. A intensa atividade turística aliada à insipiente quantidade de dispositivos de regramento, tem contribuído para a degradação de seus ecossistemas, ameaças de interdição e preocupação para quem depende do produto turismo do Parque. O presente artigo busca discutir teoricamente a importância da gestão integrada (GI) presente na Política Nacional de Resíduos Sólidos - PNRS - bem como o Estudo de Impacto Ambiental - EIA - citado na Política Nacional do Meio Ambiente - PNMA - no direcionamento de melhores práticas de gestão para a área natural protegida em questão. A revisão bibliográfica sobre as principais temáticas, bem como as visitas ao Parque no decorrer dos últimos anos, permitiram que os autores elencassem direcionamentos práticos. O manuscrito encerra com uma crítica ao abismo existente entre a legislação ambiental e as práticas de gerenciamento, e pontua a necessidade de utilizar os princípios da GI e do ElA como norteadores das tomadas de decisão.
\end{abstract}

Palavras-chave: Unidades de conservação. Gestão integrada. Impacto ambiental.

\section{INTEGRATED MANAGEMENT AND ENVIRONMENTAL IMPACT STUDIES AS A CONTRIBUTION THE AREIA VERMELHA MARINE STATE PARK, PARAÍBA, BRAZIL}

\begin{abstract}
The Areia Vermelha Marine State Park - Pemav - is one of the Paraiba conservation units with the most challenging aspects of management and monitoring of activities. The intense tourist activity, allied to the incipient number of rules, has contributed to the degradation of their ecosystems, threats of interdiction and concern for those who depend on the tourism product of the park. This paper aims to theoretically discuss the importance of integrated management (GI) present in the National Solid Waste Policy - PNRS - as well as the Environmental Impact Study - ElA - cited in the National Environment Policy - PNMA - in the direction of best management practices for the protected natural areas. The literature review on the themes as well as the visits to the park during the last years allow the authors to suggest practical directions. The manuscript concludes with a critique of the gulf between environmental legislation and management practices as well as points to the need to use the principles of GI and EIA as guiding decision-making.
\end{abstract}

Keywords: Conservation units. Integrated management. Environmental impact.

\footnotetext{
${ }^{1}$ O presente trabalho foi realizado com apoio da Coordenação de Aperfeiçoamento de Pessoal de Nível Superior - Brasil (Capes) - Código de Financiamento 001. The study was financed in part by the Coordenação de Aperfeiçoamento de Pessoal de Nível Superior - Brazil (Capes) Finace Code 001.

${ }^{2}$ Mestre e doutorando em Desenvolvimento e Meio Ambiente pela Universidade Federal da Paraíba (UFPB).thi_ago@outlook.com

${ }^{3}$ Doutor em Geografia pela Universidade Estadual Paulista Júlio de Mesquita Filho (Unesp). Professor da Universidade Federal da Paraíba (UFPB). eduvianalima@gmail.com
} 
O fortalecimento das economias mundiais, a teia dinâmica da globalização e o avanço da tecnologia, têm despertado discussões sobre o meio ambiente em escala planetária (SILVA, 2016). Diversos países têm voltado suas atenções, em seus territórios, para agir dentro de uma estrutura legal e a se comprometer com princípios e normas que atenuem os impactos gerados por suas atividades produtivas.

No Brasil, por exemplo, desde o início do século há um movimento da esfera legislativa em pontuar diretrizes que interfiram positivamente em favor do meio natural e na promoção da boa qualidade ambiental para a biodiversidade (LAPYDA, 2018). Mais recentemente, tem havido compreensão de que as políticas públicas de gestão destes espaços precisam de legitimidade da população e participação efetiva na recuperação, conservação e uso sustentável (OLIVEIRA, et al., 2016).

Desde a Carta Magna de 1988 e com ela toda a transformação ocorrida com o passar dos anos, diversas leis e decretos ganharam força e representatividade perante a sociedade brasileira. Como expõe Szklarowsky (2001), a Constituição de 1988 é um documento de significativa importância na defesa do meio ambiente e do patrimônio genético, que busca as melhores condições de permanência para a natureza, cabendo ao Estado e à sociedade civil o dever de preservá-lo.

Por conseguinte, políticas formaram-se a partir da Magna Carta brasileira, fruto da crescente demanda internacional por debater a realidade e o futuro dos recursos naturais, debates esses que tiveram suas primeiras agitações no clube de Roma em 1968 a na conferência de Estocolmo em 1972. Outros documentos e encontros mundiais surgiram até mesmo antes da Constituição, como a Política Nacional do Meio Ambiente PNMA -, que já apresentava as definições iniciais do meio ambiente como um sistema complexo e repleto de relações, aparecendo no cenário brasileiro em 1981.

A PNMA tinha como estratégia central a melhoria e recuperação da qualidade ambiental propícia à vida, e assegurar condições ao desenvolvimento socioeconômico, interesses de segurança nacional e proteção da dignidade da vida humana (BRASIL, 1981).

Anos após a Constituição de 1988, com o encontro da Rio 92, diversos Estados nacionais passaram a considerar inúmeros dispositivos legais voltados ao meio ambiente, trazendo para dentro de suas políticas nacionais a importância de se preservar as riquezas presentes no meio ambiente e em seu patrimônio genético.

O Sistema Nacional de Unidades de Conservação - SNUC -, com lei de criação do ano 2000 , surge dentro desta realidade em que a proteção da fauna e da flora nativas, assim como significativas parcelas da cobertura vegetal, passam a assumir uma prioridade emergente na discussão global sobre meio ambiente. Sancionada a Lei do SNUC, em seguida são criadas diversas unidades de conservação, visando à proteção dos recursos bióticos bem como a conservação dos espaços físicos, culturais e tradicionais destes mesmos espaços naturais (OVIEDO, 2013; GAMBA; RIBEIRO, 2017).

Para Lira et al. (2008), as Unidades de Conservação - UCs - trazem uma preocupação ambiental maior no plano jurídico, aumentando tanto a legislação existente sobre proteção ambiental quanto o seu escopo de proteção, submetendo ao crivo da avaliação desta legislação vários setores da atividade humana. 
Na Paraíba, as unidades estaduais ganharam sua apropriação no início do século, quando surgiram as primeiras reservas e parques de conservação. Foi após a Lei do SNUC que ganharam ampla visibilidade com a criação dos Parques de Areia Vermelha, Pedra da Boca e da Mata do Xém-Xém. Em seguida, a população passou a compreender o papel das áreas protegidas e os desafios envoltos à gestão ambiental por conviverem mais próximas às áreas (FONSECA; OLIVEIRA, 2016).

$O$ artigo centra o debate em três momentos: uma revisão do SNUC até a data de formação das unidades de conservação paraibanas, a gestão integrada presente na Política Nacional de Resíduos Sólidos - PNRS - com contributos para o Parque Estadual Marinho de Areia Vermelha - Pemav -, e assinala a importância do Estudo de Impacto Ambiental - ElA - da Política Nacional do Meio Ambiente, para melhor adequação das atividades na região de Areia Vermelha.

São feitas contribuições dos autores para a gestão da Superintendência de Administração do Meio Ambiente - Sudema - e aponta-se diretrizes para a melhoria nos aspectos do uso equilibrado do espaço e para a conservação do Pemav.

A metodologia empregada apresenta-se de cunho exploratório e método qualitativo, por se tratar de uma interpretação dos principais temas envoltos às áreas naturais protegidas bem como por analisar, por meio de visitas in loco, as condições de gestão e monitoramento das atividades no Pemav.

\section{REVISÃO LITERÁRIA}

\section{Breve histórico das áreas protegidas, do Sistema Nacional de Unidades de Conservação - SNUC - e do Parque Estadual Marinho de Areia Vermelha - Pemav}

As últimas décadas têm trazido para o cenário mundial fortes discussões acerca do futuro da humanidade e da redução dos recursos naturais disponíveis. Por muito tempo a preocupação com a limitação de uso dos elementos da natureza foi desprezada, levando a humanidade a questionar seus hábitos de exploração secular, seu estilo de vida baseado no consumo desenfreado e seu modo de produção predatório (MARQUES; SILVA, 2018).

De acordo com o Instituto Brasileiro de Meio Ambiente e dos Recursos Naturais Renováveis - Ibama, "as áreas protegidas no mundo datam desde o ano 250 a.C., quando na Índia já se protegiam certas espécies de animais, peixes e importantes áreas florestadas para preservação".

O século 19 registrou as primeiras percepções de espaços naturais protegidos e passou a considerar as grandes áreas verdes sob tutela do Estado. $\mathrm{O}$ movimento ambientalista na década de 60 do século 20 e os grandes acordos mundiais mediados pela Organização das Nações Unidas - ONU - anos mais tarde, com marco central na ECO 92, registram o ápice da discussão sobre áreas protegidas em escala global (BARRETTO FILHO, 2004; SILVA; SOUZA, 2009).

O marco histórico da criação de áreas verdes preservadas é o Parque Nacional de Yellowstone, criado em 10 de março de 1872 nos Estados Unidos, nos Estados de Wyoming, Montana e Idaho, tornando-se o primeiro parque nacional de que se tem 
conhecimento no mundo, com o intuito de cuidado e permanência dos ecossistemas locais (SILVA; SOUZA, 2009; OVIEDO, 2013). Saiu-se de um ideal preservacionista para uma perspectiva conservacionista, com avanços na categorização das áreas protegidas e no olhar atento aos conflitos existentes em torno das UCs e dos embaraços sócio econômicos existentes (PELIZZARO et al., 2015).

AA Tabela 1 aponta o percentual de conservação da biodiversidade potencial nos dez países de cada continente, segundo a lista da Global Environment Facility Benefits Index - Gefbi - por continente. O cenário mostra que, atualmente, as maiores nações em dimensões geográficas também apresentam a grande biodiversidade do planeta, dentre elas Brasil, Estados Unidos e Austrália. Estes mesmos países têm atingido os principais critérios, segundo a Gefbi, com maior potencial de eficácia na conservação das áreas protegidas (PELIZZARO et al., 2015).

Tabela 1 - Classificação dos países com maior biodiversidade por continente segundo o Global Environment Facility Benefits Index (Gefbi)

\begin{tabular}{|c|c|c|c|c|c|c|c|c|c|}
\hline AMÉRICA & $\mathbf{I}$ & ÁFRICA & $\mathbf{I}$ & ÁSIA & $\mathbf{I}$ & EUROPA & $\mathbf{I}$ & OCEANIA & $\mathbf{I}$ \\
\hline BRASIL & $\mathbf{1 0 0}$ & MADAGASCAR & $\mathbf{2 9 , 2 2}$ & INDONÉSIA & $\mathbf{8 0 , 9 6}$ & RÚSSIA & $\mathbf{3 4 , 1 3}$ & AUSTRÁLIA & $\mathbf{8 7 , 6 9}$ \\
\hline $\begin{array}{c}\text { ESTADOS } \\
\text { UNIDOS }\end{array}$ & $\mathbf{9 4 , 2 2}$ & $\begin{array}{c}\text { ÁFRICA } \\
\text { DO SUL }\end{array}$ & $\mathbf{2 0 , 7 4}$ & CHINA & $\mathbf{6 6 , 6 1}$ & ESPANHA & $\mathbf{6 , 8 4}$ & $\begin{array}{c}\text { PAPUA NOVA } \\
\text { GUINÉ }\end{array}$ & $\mathbf{2 5 , 4 3}$ \\
\hline MÉXICO & $\mathbf{6 8 , 6 8}$ & $\begin{array}{c}\text { REP. DEMOC. } \\
\text { DO CONGO }\end{array}$ & $\mathbf{1 9 , 9 5}$ & ÍNDIA & $\mathbf{3 9 , 9 3}$ & TURQUIA & $\mathbf{6 , 2 3}$ & $\begin{array}{c}\text { NOVA } \\
\text { ZELÂNDIA }\end{array}$ & $\mathbf{2 0 , 2 3}$ \\
\hline COLÔMBIA & $\mathbf{5 1 , 5 1}$ & TANZÂNIA & $\mathbf{1 4 , 7 6}$ & JAPÃO & $\mathbf{3 6 , 9 6}$ & PORTUGAL & $\mathbf{5 , 5 2}$ & $\begin{array}{c}\text { NOVA } \\
\text { CALEDÔNIA }\end{array}$ & $\mathbf{8 , 5 5}$ \\
\hline PERU & $\mathbf{3 3 , 3 6}$ & CAMARÕES & $\mathbf{1 2 , 5 1}$ & FILIPINAS & $\mathbf{3 2 , 3 3}$ & FRANÇA & $\mathbf{5 , 3 0}$ & $\begin{array}{c}\text { POLINÉSIA } \\
\text { FRANCESA }\end{array}$ & $\mathbf{4 , 5 7}$ \\
\hline EQUADOR & $\mathbf{2 9 , 3 4}$ & QUÊNIA & $\mathbf{8 , 8 2}$ & MALÁSIA & $\mathbf{1 3 , 8 6}$ & ITÁLIA & $\mathbf{3 , 8 5}$ & $\begin{array}{c}\text { ILHAS } \\
\text { SALOMÃO }\end{array}$ & $\mathbf{4 , 3 7}$ \\
\hline VENEZUELA & $\mathbf{2 5 , 3 2}$ & ETIÓPIA & $\mathbf{8 , 3 8}$ & VIETNÃ & $\mathbf{1 2 , 0 5}$ & $\begin{array}{c}\text { REINO } \\
\text { UNIDO }\end{array}$ & $\mathbf{3 , 5 5}$ & FIJI & $\mathbf{3 , 8 6}$ \\
\hline ARGENTINA & $\mathbf{1 7 , 7 1}$ & ANGOLA & $\mathbf{8 , 2 6}$ & MYANMAR & $\mathbf{1 0 , 0 2}$ & GRÉCIA & $\mathbf{2 , 8 0}$ & $\begin{array}{c}\text { ESTADOS FED. } \\
\text { DA MICRONÉSIA }\end{array}$ & $\mathbf{2 , 6 1}$ \\
\hline CHILE & $\mathbf{1 5 , 3 2}$ & MOÇAMBIQUE & $\mathbf{7 , 1 8}$ & TAILÂNDIA & $\mathbf{8 , 0 2}$ & NORUEGA & $\mathbf{1 , 3 1}$ & $\begin{array}{c}\text { ILHAS MARIANAS } \\
\text { DO NORTE }\end{array}$ & $\mathbf{2 , 2 4}$ \\
\hline BOLÍVIA & $\mathbf{1 2 , 5 5}$ & SOMÁLIA & $\mathbf{6 , 0 8}$ & SRI LANKA & $\mathbf{7 , 8 6}$ & BULGÁRIA & $\mathbf{0 , 8 1}$ & VANUATU & $\mathbf{2 , 0 9}$ \\
\hline
\end{tabular}

Fonte: Adaptado de Pelizzaro et al., 2015. Elaborada com base em WORLD BANK (2019). I = índice Gefbi.

No Brasil, o histórico de áreas preservadas surge um pouco mais tarde, se comparado a outras nações do mundo, a exemplo dos EUA e de países da Europa. Foi somente em junho de 1937, com base no Código Florestal de 1934, considerado ineficaz por diversos autores, que foi criado o primeiro parque nacional - o de Itatiaia -, localizado nos municípios de Itatiaia e Resende, no Rio de Janeiro, motivado pela realidade de destruição florestal vivida no país naquele momento (ICMBio, 2018). Dois anos depois surgem também os Parques de Iguaçu no Paraná e o Parque Nacional da Serra dos Órgãos no Rio de Janeiro (RYLANDS; BRANDON, 2005).

Dentre as características presentes no código florestal de 1934 e que permanecem até hoje com a promulgação da Lei 12.651 de 2012, encontra-se menção à proteção da vegetação nativa: "Art. 2: As florestas existentes no território nacional e as demais formas de vegetação nativa, reconhecidas de utilidade às terras que revestem, são bens de interesse comum a todos os habitantes do País". 
A iniciativa pela criação de parques nacionais espalhou-se no Brasil principalmente após a Assembleia da International Union for Conservation of Nature - IUCN -, os diversos Congressos Internacionais e a Convenção Pan-americana sobre a Proteção da Natureza em 1940 na cidade de Washington, quando deu respaldo para que em 1948 fossem definidos os conceitos de parques e reservas nacionais, monumentos naturais e reservas estritamente silvestres (VALLEJO, 2002). Os primeiros anos do século 21 marcam os direcionamentos globais sobre proteção do material natural e em como institucionalizar áreas protegidas sob tutela do Estado (SILVA, 2008).

A necessidade de manter espaços naturais longe da exploração humana trouxe para as décadas mais recentes um movimento de segregação de espaços verdes para uso equilibrado com a comunidade próxima (ou com turistas), bem como o estabelecimento de áreas de proteção integral. Este fenômeno intensificou-se durante o pós-guerra com a formação de diversos parques naturais pelo mundo, e no Brasil um movimento mais forte veio próximo ao ano 2000. Esse desdobramento tornou o processo de consciência ambiental algo factível para esta e as próximas gerações (GAMBA; RIBEIRO, 2017).

Em paralelo à preocupação sobre a permanência dos recursos naturais para as gerações seguintes e com a tentativa de geração de renda por meio do turismo, os tais parques foram modificando-se e passaram a receber diversas definições de acordo com suas características naturais, e, dentre elas, aparecem as chamadas Unidades de Conservação - UCs.

Para entender a institucionalização da Lei 9.985/2000, que trata das Unidades de Conservação, é necessário retornar, primeiramente, aos primórdios do SNUC em meados dos anos 70, quando o antigo Instituto Brasileiro de Desenvolvimento Florestal (IBDF) já apontava a importância do Plano do Sistema Nacional de Unidades de Conservação do Brasil, que tratava de objetivos específicos necessários à conservação de certas áreas da natureza (MMA, 2018).

Com a Lei 9.985 reúnem-se todos os conceitos gerais sobre categorias de manejo, tipos de unidades e aponta-se diretrizes de gestão voltadas à boa permanência do local. Entende-se como unidade de conservação toda área protegida que possui regras próprias de uso, com a finalidade própria de proteção de espécies vegetais ou animais, de tradições culturais, de belezas paisagísticas ou de fontes científicas, dependendo da categoria em que se enquadra (GAMBA; RIBEIRO, 2017).

Para os tipos de unidades torna-se essencial diferenciar que está presente na Lei uma compreensão diferenciada entre unidades de conservação de uso sustentável e unidades de conservação de proteção integral. A primeira contempla áreas em que pode existir algum tipo de intervenção humana desde que com o compromisso de compensação ambiental. A segunda, portanto, proíbe qualquer interferência humana, tornando-se espaço direcionado para o ecoturismo e o lazer equilibrados.

Difundido largamente entre vários autores, o SNUC surge num momento bastante propício do movimento ambiental brasileiro, especialmente em sua contribuição para o marco regulatório em Estados e municípios (SILVA; SOUZA, 2009). É claramente evi- 
denciado, em outras revisões bibliográficas, que o fortalecimento do SNUC tornou o desenrolar conservacionista um ponto alto no debate ambiental, mesmo que de forma desordenada e pouco efetiva em muitos dos espaços nacionais, em âmbito federal e da América Latina (FOPPA et al., 2018; RIONDET-COSTA et al., 2018).

No Estado da Paraíba as primeiras UCs datam de 1992, com a criação da Reserva Ecológica Mata Pau-Ferro, Reserva Ecológica Mata do Rio Vermelho, Parque Pico do Jabre e o Monumento Natural Vale dos Dinossauros. Esse ano foi um marco nos avanços quanto à criação das unidades, pois pouco antes, em 1989, tinha sido criado o Ibama, e, com base no Plano do Sistema de Unidades de Conservação, no Projeto de Lei de no 2.892 de 92, fortaleceu-se base para a instituição do SNUC no país (RYLANDS; BRANDON, 2005).

Atualmente, de acordo com dados oficiais da Sudema, existem 6 unidades de conservação sob domínio federal, 15 unidades estaduais, 7 municipais e 11 unidades particulares, que totalizam 39 Unidades de Conservação na Paraíba (Anexo 1). Estas condições tornam o Estado um multiplicador de áreas conservadas e de forte potencial na proteção da biodiversidade local, que abrangem os biomas Marinho, Mata Atlântica e a Caatinga.

Sob a gestão do governo estadual encontra-se o Parque Estadual Marinho de Areia Vermelha, criado com o decreto 21.263/2000, tornando o local uma Unidade de Conservação, e, em 2007 (pela Portaria 002), é formalizado o plano emergencial de gestão. Exatos dez anos depois, em 2017 o plano de manejo é finalmente aprovado com anuência dos atores envolvidos na atividade do parque. ${ }^{4}$

A área que compreende o Pemav possui 230,91 hectares, uma dimensão de quase $3 \mathrm{~km}$ de extensão no sentido norte-sul (LOURENÇO, 2010), e "uma biodiversidade marinha composta principalmente por espécies de corais, moluscos e peixes" (SUDEMA, 2018). Esse espaço natural (Figura 1), que é conhecido por sua prioridade na inserção dos roteiros turísticos paraibanos, sofre com a ausência de normas concretas de acesso e controle da atividade econômica do turismo.

\footnotetext{
${ }^{4}$ Disponível em: http://sudema.pb.gov.br/noticias/governo-define-plano-de-manejo-do-parque-estadual-marinho-de-areia-vermelha-1
} 
Mapa 1 - Parque Estadual Marinho de Areia Vermelha-Pemav - Cabedelo - Paraíba

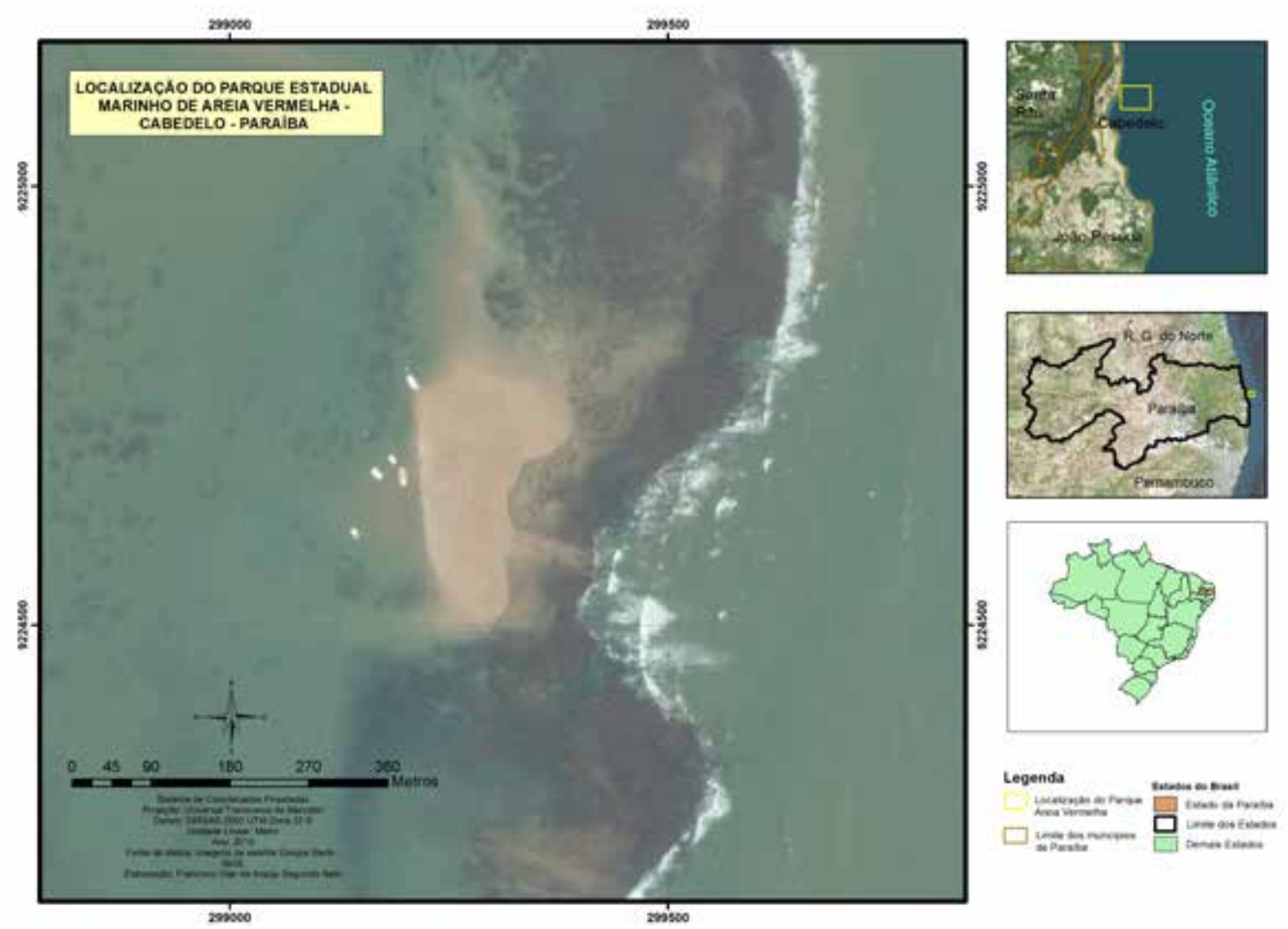

Fonte: SILVA, 2016. Imagem de Francisco Vilar de Araújo Segundo Neto.

O Parque de Areia Vermelha sofreu três ameaças de interdição pelo Ministério Público da Paraíba (MPPB) ao longo dos últimos anos. Fruto da morosidade na elaboração do plano de manejo e da ausência de uma sede fixa em terra, algo que deveria existir desde 2007, quando a Sudema-PB criou o Conselho Gestor do parque, os desafios que cercam o espaço permanecem evidenciados na dimensão que a temática do Pemav atinge em âmbito estadual e na relevância econômica que a atividade exerce para o município de Cabedelo.

\section{A gestão integrada e sua contribuição para o Parque de Areia Vermelha}

Presente na Política Nacional de Resíduos Sólidos, em seu artigo sétimo, inciso sétimo, quando descreve: "VII. Gestão integrada dos resíduos sólidos" (BRASIL, 2010), este estilo de gestão compreende uma visão sistêmica das decisões governamentais em consolidar forças no gerenciamento de resíduos sólidos nacionais, dispondo princípios, objetivos e instrumentos que norteiem essa questão.

Todo o histórico de dispositivos legais até a formação, em 2010, da PNRS, mostra que a gestão integrada é capaz de otimizar o processo de manejo dos resíduos sólidos urbanos. Quase nove anos após ter sido sancionada a Lei $12.305 / 2010$, entretanto, os desafios enfrentados pelas grandes cidades brasileiras quanto ao descarte adequado encontram-se tão complexos quanto o período anterior à lei (LAVNITCKI; BAUM; BECEGATO, 2018). 
A integração dos diversos setores e espaços públicos é capaz de proporcionar reduções certificadas de descarte de material sólido, consolidando um caminho para a sustentabilidade ambiental, social e econômica em cada município brasileiro (MESQUITA JUNIOR, 2007). Neste mesmo entendimento, pode-se relacionar a importância da gestão integrada no processo de administração, construção e manejo das unidades de conservação.

As unidades de conservação no Brasil têm um histórico recente se comparadas a outros países do norte do planeta, onde a conservação de áreas naturais data de mais de cem anos (BRITO, 2000). No Estado da Paraíba as primeiras UCs são de 1992, e em 2000 há um aumento significativo do número de áreas protegidas estaduais, alcançando a marca de oito espaços conservados com respaldo legal. Estes locais foram legalmente instituídos e deveria ter sido criado um comitê gestor para cada unidade.

O Parque de Areia Vermelha, por exemplo, recebeu seu plano de manejo em 2017, quando encerrou o prazo do Plano de Ação Emergencial - PAE -, criado pela Superintendência de Administração do Meio Ambiente. A pressão dos atores ambientais locais culminou na elaboração e posterior aprovação do documento. Esse é um contraponto complexo, já exaustivamente citado por diversos autores, sobre o distanciamento entre o que há na legislação ambiental no Brasil - e em seus Estados e municípios - e suas diretrizes reais de gestão.

Segundo Lourenço (2010), para que haja o real ordenamento turístico do Pemav há muito o que se fazer, a começar pelo próprio plano de manejo. A autora destaca que são insuficientes as práticas hoje estabelecidas se contrapostas à capacidade de suporte do ecossistêmica local e o fluxo contínuo da atividade turística. Por ser uma rota litorânea bastante procurada e de elevada visitação o ano inteiro, a necessidade de mais regramento em diversos aspectos da gestão do parque (SILVA, 2008) torna-se essencial para uma continuidade equilibrada do espaço.

Quando se trata de uma abordagem integrada, passa-se a refletir sobre como trazer as diretrizes legais e gerenciais à realidade materializada, ou seja, transformar as ideias em ações concretas para o dia a dia de quem convive com o ambiente próximo (GAMBA; RIBEIRO, 2017). Pensar que uma gestão integrada envolve todas as partes no processo da atividade, compartilha de um mesmo objetivo e torna o papel individual imprescindível na formação do esforço coletivo, é um direcionador para novos formatos de administração local.

Este comprometimento torna-se essencial desde os representantes que compõem a esfera pública, passa pelos que dependem da atividade turística direta ou indiretamente e encerra o ciclo com os turistas na manutenção do ambiente limpo e livre do descarte inadequado.

No campo da ciência da administração, por exemplo, compreende-se a gestão estratégica como saída para o sucesso de um determinado negócio. Este entendimento busca convencer todos os envolvidos no processo da atividade ou da prestação de serviço que o sucesso depende muito mais de como se gerencia e das ferramentas disponíveis do que do planejamento em si anteriormente realizado (LIMA et al., 2007). Nesse 
caso, envolvidos no processo da atividade turística estão os visitantes, o corpo gestor, os estudiosos e a gestão pública direta, e a eficácia da abordagem se manifestará do ente público, com a disposição de regras para a atividade turística.

A produção da Cerezini (2018) é um destaque substancial sobre o aumento de sistemas de gestão capazes de integralizar ferramentas de gerenciamento ambiental mediante princípios da GI. O estudo definiu condições de planejamento e acompanhamento sobre o uso sustentável dos recursos hídricos e resultou em impactos diretos na conjuntura para a análise de bacias hidrográficas. A gestão integrada foi utilizada como norteadora de olhares sensíveis para os recursos hídricos nacionais, de forma sistêmica e agregada.

A Figura 1 a seguir visualiza uma relação integrada de condições capazes de ponderar demandas econômicas, institucionais, ambientais e sociais envoltas aos espaços conservados.

Faz-se, neste sentido, uma reflexão direcionada para Areia Vermelha como um bem intangível e de difícil mensuração quantitativa. É preciso pensar numa gestão que respeite valores construídos de quem vive e depende das atividades do Parque, que construa processos formais de uso e que forneça incentivos ao bom gerenciamento, desenvolvimento local e continuidade do turismo.

Figura 1 - Núcleo do modelo de gestão integrada dos ativos intangíveis

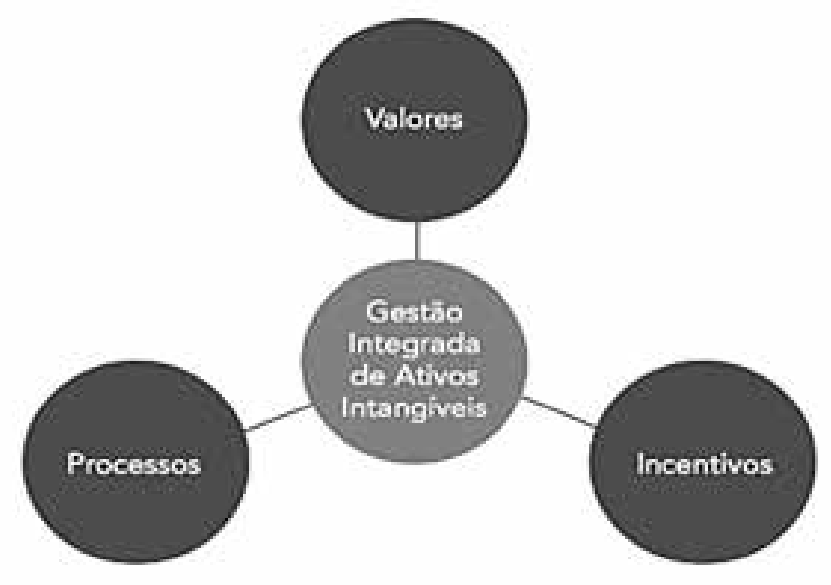

Fonte: ALMEIDA et al., 2017.

É com pautas de regramento real e compromisso com um ambiente saudável que os processos de gestão serão decisivos para êxito no Pemav. Há uma necessidade de suporte estrutural para pesquisas científicas e auxílio para pesquisadores (MEDEIROS, 2006) no que se refere à capacidade do ente governamental em prover estas informações. No caso de Areia Vermelha em especial, a gestão estratégica tende a contribuir mais fortemente com as tomadas de decisão, impactando em boas condições da atividade econômica e do meio natural.

Destacamos dois pontos de grande relevância na tentativa de um olhar com respaldo na gestão integrada: a necessidade de capacitar recursos humanos com o conhecimento necessário dos aspectos ambientais e em se pensar no produto turismo como 
algo a ser considerado no longo prazo e de forma duradoura (ALMEIDA et al., 2017). Acima destes dois pontos há uma boa qualidade ambiental que precisa ser mantida, e, ainda, o respeito aos costumes de comunidades próximas.

Uma última contribuição surge com a responsabilidade compartilhada, também presente na Política Nacional de Resíduos Sólidos. O documento faz referência ao ciclo de vida do produto, que responsabiliza tanto os fornecedores quanto os importadores, distribuidores e consumidores dentro do processo produtivo. Esta compreensão nos remete a uma reflexão sobre compartilhar responsabilidades com a atividade do Parque. Associações, Sindicatos, o Conselho Gestor, a Sudema e o próprio governo estadual, devem dispor de mecanismos colaborativos para todos os envolvidos.

Uma unidade de conservação, como o Pemav, exige um pensar mais amplo de comprometimento com o bem natural, na permanência dos valores ali estabelecidos e dos conceitos éticos que circundam a plena conservação (SCAFF; TUPIASSU, 2004). Não está tão distante imaginar que há espaços em que a eficiência no gerenciamento tem contribuído para uma boa continuidade do produto turístico ao longo do tempo, a exemplo do Parque Nacional da Serra da Capivara no Piauí (BRANDÃO; SCHIAVETTI, 2017), do Parque Estadual de Vila Velha no Paraná (MANTILLA; SILVEIRA; TELES, 2017) e do Parque Natural Municipal Corredores da Biodiversidade em Sorocaba, São Paulo (OLIVEIRA et al., 2016).

É preciso enfatizar que a gestão integrada necessita da participação de todos e, ao se misturar com diretrizes da gestão estratégica, aponta na direção de um convencimento das partes acerca de compromissos individuais (PRADO et al., 2018). Essa correlação dos estilos de gestão torna possível um nível de excelência, sempre a refletir sobre o grau de risco, as possíveis falhas e uma tomada de decisão corretiva manifestada por esforços complementares e sinérgicos (LIMA, 2007).

\section{A importância do Estudo de Impacto Ambiental - EIA - para o Pemav}

Em consonância com a Carta Magna brasileira de 1988, em seu artigo 225, quando afirma que "todos têm direito ao meio ambiente ecologicamente equilibrado, bem de uso comum do povo e essencial à sadia qualidade de vida, impondo ao Poder Público e à coletividade o dever de defendê-lo e preservá-lo para a presente e as futuras gerações" (BRASIL, 1988), existem medidas que visam a garantir a efetividade de ações concretas em favor do meio ambiente natural.

Um dos principais instrumentos legais de medição do embate entre as demandas econômicas e a proteção do meio natural é o Estudo de Impacto Ambiental - ElA -, presente na Política Nacional do Meio Ambiente desde 1981. Teve trajetória de destaque nas Resoluções do Conselho Nacional do Meio Ambiente - Conama - de 1987 e 1996, e hoje encontra-se em vigor com o Decreto 4.340 de 22 de agosto de 2002 e, mais atualmente, sob os detalhes encontrados na Lei 13.668 de 2018.

O EIA destaca-se no cenário conservacionista brasileiro, logo após a Rio 92, como suporte para diversos estudos que avaliam a permanência da biodiversidade dos espaços naturais e subsidiam qualidade para o meio ambiente (BARROS et al., 2015). 0 estudo ambiental, além de prover informações acerca da realidade natural dos espaços, 
compreende também as atividades técnicas de diagnóstico natural, análise dos impactos ambientais, compreensão de medidas mitigadoras de impactos e elaboração de programa de monitoramento ambiental (IBAMA, 2016).

Campos e Silva (2012) definem o EIA como artifício de planejamento tendente a viabilizar o estabelecimento de empreendimentos públicos e privados de forma segura e equilibrada em termos socioeconômicos e ambientais. Cervi (2010) classifica como um mecanismo de ajuste e qualidade para o meio ambiente. Estas ponderações apontam o instrumento como norteador e essencial para continuidade das atividades econômicas.

Qualquer unidade de conservação, por priorizar o cuidado ambiental e ter compromisso com o desenvolvimento local, exprime uma necessidade de conhecer princípios do EIA. Embora o foco do mecanismo esteja voltado para a criação de empreendimentos privados com diagnóstico das condições ambientais e possíveis impactos (CAMPOS; SILVA, 2012), o EIA pode ser um potencial balizador entre a conservação do espaço e a atividade turística, por exemplo. A manutenção das espécies vegetais nativas como estratégia de equilíbrio para o meio natural local, é uma perspectiva oriunda das diretrizes previstas no documento técnico (LIBÓRIO, 2017).

Segundo Lira et al. (2008), a inter-relação estabelecida entre o meio natural e a atividade que se pretende desenvolver, concretizada pela possibilidade de um estudo prévio ambiental, permite soluções antecipadas quanto ao trato do meio ambiente e seus efeitos no desenvolvimento socioambiental. Há possibilidade de desenvolvimento que contribua para a recuperação da qualidade ambiental, a prevenção de riscos e a melhoria das oportunidades de modos de vida tradicionais (SANCHÉZ, 2017).

O Estudo de Impacto Ambiental surge como a consagração de uma regra de julgamento da atividade judicial na defesa do meio ambiente quanto a ocorrências efetivas ou potenciais de degradação ambiental (MIRRA, 2001). Presente desde o ano 2000 na Lei do SNUC em seu artigo 36, o EIA é um dos mais significativos instrumentos de compatibilização de interesses econômicos e ambientais, promovendo o desenvolvimento econômico e a qualidade do meio ambiente (MILARÉ, 2006).

No Estado da Paraíba as unidades de conservação não contam com efetivas políticas de gestão e monitoramento acerca dos estudos de impactos na atuação das atividades humanas. Torna-se algo especialmente direcionado ao âmbito da construção civil e da extração mineral. Desde 2011, conforme destaca a Sudema, ${ }^{5}$ há obrigatoriedade de Audiências Públicas em todos os processos de licenciamento ambiental nos quais requisita-se Estudo de Impacto Ambiental e Relatório de Impacto Ambiental - Rima. Seria, entretanto, uma direção bastante razoável este tipo de prática de monitoramento também para espaços de intensa atividade turística sob responsabilidade do governo estadual.

Pelo fato de o ente público não direcionar ações desta natureza para espaços onde a atividade turística esteja presente, a pressão torna-se mais forte nas questões relativas à especulação imobiliária, pesca esportiva e a segunda residência para lazer e descanso (FOPPA et al., 2018).

Destaca-se, a seguir, as unidades de conservação do Estado da Paraíba nos três âmbitos de gestão: municipal, estadual e federal, segundo fonte da Sudema.

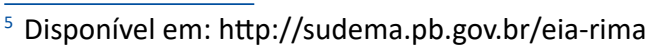




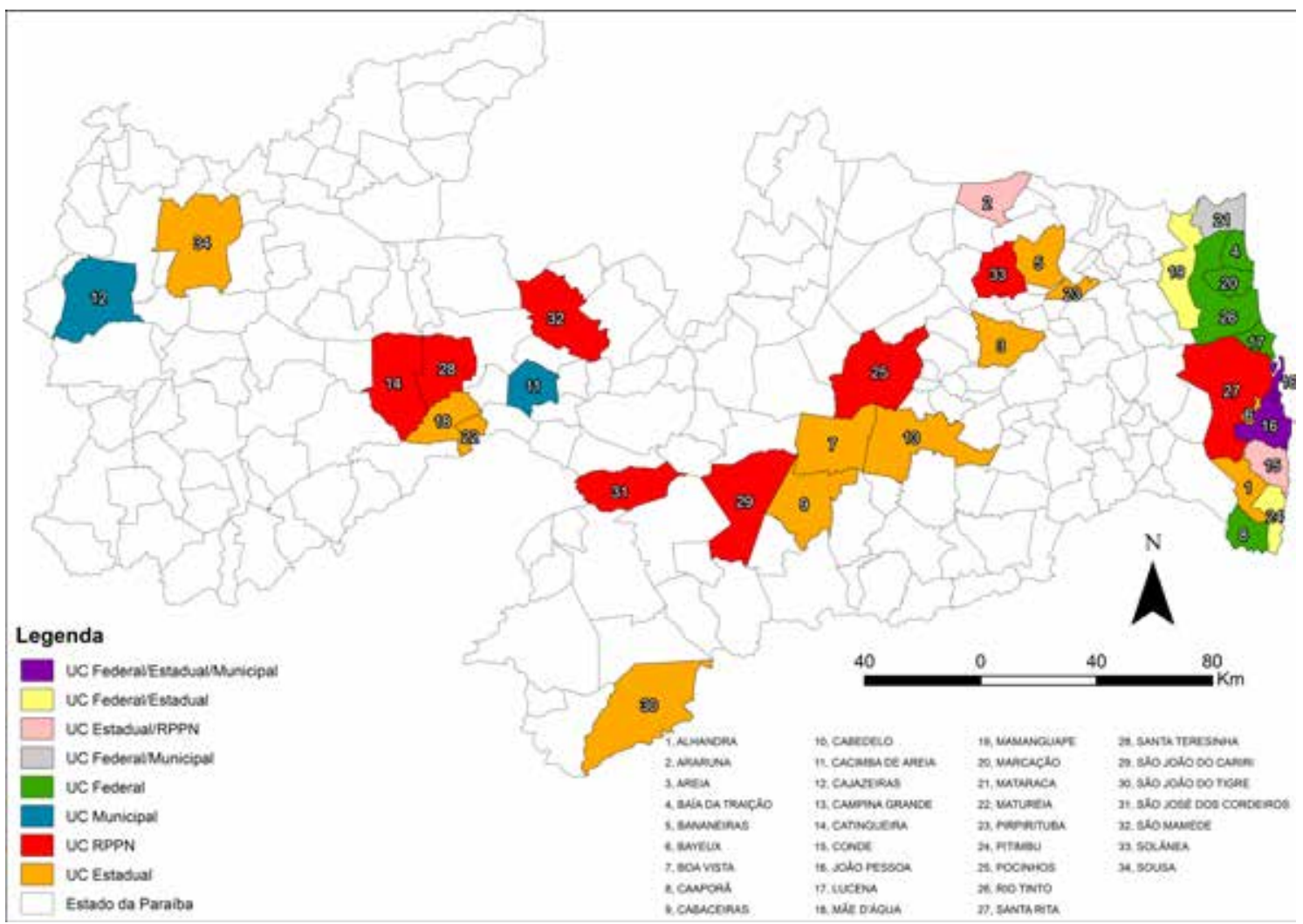

Fonte: Adaptado de Sudema, 2018. Imagem de Francisco Vilar de Araújo Segundo Neto.

Como destaca Cavalcante (2009), existe uma grande carência de infraestrutura para receber os turistas e no suporte a pesquisadores, total falta de engajamento da esfera pública com as unidades de conservação, principalmente no que respeita à educação ambiental aos turistas, e a ausência de integração da população local com o entorno conservado. $O$ que há são práticas pontuais e ainda insipientes.

No Pemav a realidade também se encontra deste modo. A ausência de estudos sobre os impactos do turismo e até a dificuldade de mensurá-los diante da necessidade de conservação ambiental, contrariando, muitas vezes, interesses econômicos, inibe mais fortemente o processo decisório (GAMBA; RIBEIRO, 2017) e de políticas públicas ambientais direcionadas.

Os ambientes de recifes de corais presentes em Areia Vermelha, sofrem com os efeitos globais de aumento da temperatura e do do nível dos oceanos. A questão torna-se ainda mais complexa, pois o espaço encontra-se em "zonas costeiras, de fácil acesso, com pisoteio e degradação, interferindo diretamente na saúde dos corais" (MELO; LINS; ELOY, 2014, p. 80). Ao atingir a boa saúde dos corais, os efeitos partem para todo o ecossistema local e para a continuidade da própria atividade turística.

Entende-se que é um movimento global do aumento da temperatura e do nível dos oceanos, e isso impacta em ambientes de corais (FREITAS; OLIVEIRA; KIKUCHI, 2012), como também é percebido na Austrália e nas Lagoas da Caledônia, na França. Cita-se o exemplo do impacto na vida marinha dos corais na tentativa de demonstrar que o atual formato da gestão do turismo é mais profundo e desafiador do que simplesmente o cálculo da capacidade de carga para o Pemav. 
Em quase 19 anos após sua criação, é, por assim dizer, inaceitável um espaço turístico tão visitado e tão importante, do ponto de vista ambiental, não cobrir integralmente demandas legais e administrativas de funcionamento. É de extrema importância que continuem as cobranças e as solicitações às autoridades competentes para a efetividade de diretrizes legais e gerenciais de bom funcionamento da UC (LOURENÇO, 2010).

Cavalcante (2009), Lourenço (2010), Melo, Lins e Eloy. (2014) e Gamba e Ribeiro (2017) concordam quando o assunto é gestão. O cerne dos problemas persiste, ora em sua deficiência, ora em sua ausência, nas mais diversas realidades. É desanimador tentar propor ações de melhoria quando a própria esfera pública, responsável pela plena gestão, se exime espontaneamente da responsabilidade com o cuidado da área.

\section{CONSIDERAÇÕES FINAIS}

É importante entender o meio ambiente como um todo de dimensão difusa, necessário à sobrevivência humana, e dele é preciso conservar, cuidar e propiciar uso correto e adequado. E vamos além: entender que somos parte e, quando se compromete o equilíbrio ambiental, naturalmente é afetada nossa sobrevivência.

A atividade turístico-recreativa tem seu papel para o desenvolvimento local que, no Estado da Paraíba, entre 2010 e 2016, incorporou os quase $80 \%$ do PIB $^{6}$ do setor de serviços. Em linhas gerais, entretanto, esta atividade será comprometida caso as regras básicas de funcionamento não sejam devidamente dispostas em um espaço de tempo mais reduzido.

Decreto e Portaria foram instituídos, assim como o próprio Plano de Ação Emergencial - PAE -, durante alguns anos e, mais recentemente, o próprio Plano de Manejo foi aprovado. Entende-se que legalmente as principais etapas foram conquistadas. É preciso, porém, seguir com os desafios: retratar o distanciamento que há entre o que legalmente foi instituído e o que se observa de práticas reais.

Após a contribuição literária, percebe-se que os dispositivos legais são de extrema importância para servir de ponto de partida para o processo decisório. É com base no embasamento legal que surge esta contribuição primária acerca do que se propor para o futuro do Pemav. É preciso, entretanto, materializar práticas reais de gestão e desenvolvimento local do espaço, em especial integrando comunidades próximas. Por isso, os autores sugerem a gestão integrada e o Estudo de Impacto Ambiental como partes contributivas da análise de gerenciamento do espaço.

A GI e o EIA surgem como caminhos capazes de apontar na direção de políticas públicas ambientais (RIBAS; GONTIJO, 2015) de mais qualidade para o meio natural de Areia Vermelha. A primeira como ferramenta conceitual capaz de fomentar diretrizes entre a parceria público-privada, e a segunda como norteadora do processo de planejamento e fiscalização da atividade, reorganizando práticas de conservação por meio da estrutura humana e material da Sudema.

Entenda-se a presente contribuição científica como um debate mais geral capaz de direcionar olhares sensíveis para a gestão ambiental em áreas protegidas do Estado da Paraíba, em especial o Pemav, por ser um dos destinos naturais mais visitados.

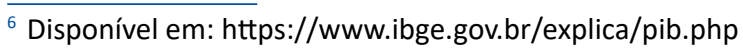


Com a atenção voltada à realidade das atividades do Parque e diante do desafiador gerenciamento pela Sudema, sugere-se a parceria público-privada como alternativa que viabilize uma melhor adequação das atividades de descarte/destino dos resíduos sólidos, bem como no controle no número de frequentadores diários. Aponta-se, também, o EIA como mecanismo norteador das atividades de planejamento e fiscalização por meio da normatização de ações claras acerca das autorizações e proibições que devam existir para o Pemav.

Os autores reforçam que o debate não se encerra por aqui e reconhecem que não é simples proporcionar impactos positivos por intermédio de um gerenciamento responsável para áreas naturais protegidas. Há interesses diversos e a necessidade de participação de muitos atores no processo decisório.

Dentro de uma gestão integrada, compartilhada e estratégica que reduza riscos e favoreça qualidade ambiental, é que se destaca a conservação de áreas protegidas. É "gerenciando mudanças da 'maneira como sempre fazemos as coisas' para 'o que precisamos fazer' para tornar o trabalho com excelência e bem-sucedido" (LIMA, 2007, p. 115).

\section{REFERÊNCIAS}

ALMEIDA, A. L. C. et al. Gestão integrada de ativos intangíveis: cultura, liderança, confiança, marca e reputação. São Paulo: Saraiva, 2017.

BARRETTO FILHO, H. T. Notas para uma história social das áreas de proteção integral no Brasil. Terras indígenas e unidades de conservação da natureza: o desafio das sobreposições. São Paulo: Instituto Socioambiental, 2004.

BARROS, E. C. et al. O instrumento de compensação ambiental no Brasil e o Estado de Minas Gerais. Revista Cerne, v. 21, n. 3, p. 449-455, 2015.

BRASIL. Política Nacional do Meio Ambiente. Lei no 6.938 de, 31 de agosto de 1981. 1981. Disponível em: http://www.planalto.gov.br/ccivil_03/leis/l6938.htm. Acesso em: 27 maio 2019.

BRASIL. Constituição da República Federativa do Brasil. 1988. Disponível em: http://www.planalto.gov.br/ ccivil_03/Constituicao/Constituicao.htm. Acesso em: 27 maio 2019.

BRASIL. Sistema Nacional de Unidades de Conservação da Natureza. Lei no 9.985 de, 18 de julho de 2000. 2000. Disponível em: http://www.planalto.gov.br/ccivil_03/LEIS/L9985.htm. Acesso em: 27 maio 2019.

BRASIL. Regulamenta Artigos da Lei 9.985 de 2000 do Sistema Nacional de Unidades de Conservação da Natureza. Decreto no 4.340 de, 22 de agosto de 2002. 2002. Disponível em: http://www.planalto.gov.br/ ccivil_03/decreto/2002/D4340.htm. Acesso em: 27 maio 2019.

BRASIL. Política Nacional de Resíduos Sólidos. Lei no 12.305 de 2 de agosto de 2010. 2010. Disponível em: http://www.planalto.gov.br/ccivil_03/_ato2007-2010/2010/lei/l12305.htm. Acesso em: 27 maio 2019.

BRASIL. Dispõe Sobre Destinação e Aplicação dos Recursos de Compensação Ambiental e Sobre a Contratação de Pessoal. Lei no 13.668 de, 28 de maio de 2018. 2018. Disponível em: http://www.planalto.gov. br/ccivil_03/_Ato2015-2018/2018/Lei/L13668.htm. Acesso em: 27 maio 2019.

BRANDÃO, C. S.; SCHIAVETTI, A. Efetividade da gestão do Parque Nacional Serra da Capivara, Piauí, Brasil: uma avaliação temporal. Revista Gaia Scientia, v. 11, n. 2, p. 32-44, 2017.

BRITO, M. C. W. Unidades de conservação: intenções e resultados. São Paulo: Fapesp; Annablume, 2000. CAMPOS, S. R. M.; SILVA, V. P. A efetividade do estudo de impacto ambiental e do licenciamento em projetos de usinas hidrelétrica. Revista Caminhos de Geografia, v. 13, n 41, p. 1-14, 2012.

CAVALCANTE, M. B. Ecoturismo no bioma caatinga: o caso do Parque Estadual da Pedra da Boca, Paraíba. Revista Nordestina de Ecoturismo, v. 2, n. 1, p. 25-38, 2009.

CEREZINI, M. T. Gestão integrada e sustentável da água em bacias hidrográficas: ferramentas, desafios e diretrizes. São Carlos, SP. 2018. Tese (Doutorado) - Universidade Federal de São Carlos, UFSCar, São Carlos, 2018.

CERVI, T. M. D. A tutela administrativa do meio ambiente: o estudo de impacto ambiental. Revista Direito e Justiça, v. 8, n. 11, p. 187-210, 2010. 
FONSECA, I. L.; OLIVEIRA, W. A. Áreas naturais protegidas, conservação e (eco) turismo: uma reflexão teórico-conceitual. Revista Turydes: Turismo y Desarrollo, v. 9, n. 20, p. 1-17, 2016.

FOPPA, C. C. et al. A (re) categorização de unidades de conservação e suas implicações aos modos de vida tradicionais. Revista Meio Ambiente e Desenvolvimento, v. 48, Edição Especial, p. 343-366, 2018.

FREITAS, L. M.; OLIVEIRA, M. M.; KIKUCHI, R. K. P. Os mecanismos de sobrevivência dos corais diante do impacto das mudanças climáticas sobre o ecossistema de recifes. Cadernos de Geociências, v. 9, n. 2, p. 142-156, 2012.

GAMBA, C.; RIBEIRO, W. C. Conservação ambiental no Brasil: uma revisão crítica de sua institucionalização. Revista de Estudios Brasileños, v. 4, n. 6, p. 146-160, 2017.

ICMBIO. Instituto Chico Mendes de Conservação da Biodiversidade. 2018. Disponível em: http://www. icmbio.gov.br/portal/. Acesso em: 15 maio 2018.

IBAMA. Instituto Brasileiro do Meio Ambiente e dos Recursos Naturais Renováveis. Avaliação de impacto ambiental: caminhos para o fortalecimento do licenciamento ambiental Federal. 2016. Disponível em: https://www.ibama.gov.br/phocadownload/noticias/noticias2016/resumo_executivo.pdf. Acesso em: 27 maio 2019.

JEANNOT, K. K.; CARVALHO, V. D. C.; FONTES, M. A. L. Efetividade de gestão do Parque Estadual do Ibitipoca, Minas Gerais. Revista Floresta e Ambiente, v. 23, n. 1, p. 11-20, 2016.

LAPYDA, I. François Chesnais. Finance capital today: corporations and banks in the lasting global slump. Boston, Brill Academic Pub., 2016. 310 p. Tempo Social Revista de Sociologia da USP, v. 30, n. 2, p. 331342, 2018.

LAVNITCKI, L.; BAUM, C. A.; BECEGATO, V. A. Política Nacional dos Resíduos Sólidos: abordagem da problemática no Brasil e a situação na Região Sul. Revista de Educação Ambiental, v. 23, n. 3, p. 379-401, 2018.

LIMA, M. F. et al. Gestão de marketing. Rio de Janeiro: Editora FGV, 2007.

LIBÓRIO, R. A. Efeitos de florestas ripárias em restauração em ecossistemas de riachos tropicais numa paisagem agrícola. 2017. Tese (Doutorado) - Universidade Federal de São Carlos, UFSCar, São Carlos, 2017.

LIRA, W. S. et al. Sustentabilidade: um enfoque sistêmico. Campina Grande: Eduep, 2008.

LOURENÇO, L. J. S. Proposta de zoneamento e capacidade de carga para o Parque Estadual Marinho de Areia Vermelha - PEMAV. 2010. Dissertação (Mestrado) - Universidade Federal da Paraíba, UFPB, João Pessoa, PB, 2010.

MANTILLA, P. G. G.; SILVEIRA, M. A. T.; TELES, M. A. Turismo e geoconservação: uma análise do modelo de gestão do uso público no Parque Estadual de Vila Velha, Paraná. Pasos - Revista de Turismo y Patrimonio Cultural, v. 15, n. 3, p. 591-602, 2017.

MARQUES, J. B.; SILVA, E. F. D. C. O papel do Estado: um retrato de administração pública na Era Vargas com um diálogo a partir da obra de Pedro Cézar Dutra Fonseca "Vargas: o Capitalismo em Construção". Revista Mosaico, v. 9, n. 2, p. 18-23, 2018.

MAZZILLI, H. N. A defesa dos interesses difusos em juízo. São Paulo: Editora Saraiva, 2009.

MEDEIROS, R. Evolution of typologies and categories of protected areas in Brazil. Revista Ambiente \& Sociedade, v. 9, n. 1, p. 41-64, 2006.

MELO, R. S.; LINS, R. P. M.; ELOY, C. C. O impacto do turismo em ambientes recifais: caso Praia do Seixas Penha, Paraíba, Brasil. Rede - Revista Eletrônica do Prodema, v. 8, n. 1, p. 67-83, 2014.

MESQUITA JUNIOR, J. M. Gestão integrada de resíduos sólidos. Coordenação Karin Segala. Rio de Janeiro: Ibam, 2007.

MILARÉ, E. Estudo prévio de impacto ambiental no Brasil, In: AB'SABER, A. N.; MÜLLER-PLANTENBERG, C. Previsão de impactos: o estudo de impacto ambiental no Leste, Oeste e Sul. Experiências no Brasil, na Rússia e na Alemanha. 2. ed. 2a reimp. São Paulo: Edusp - Editora da Universidade de São Paulo, 2006. p. 50-83.

MIRRA, Á. L. V. Direito ambiental: o princípio da precaução e sua aplicação judicial. Revista Busca Legis, $\mathrm{n}$. 21, p. 1-12, 2001.

MMA. Ministério do Meio Ambiente. 2018. Disponível em: http://www.mma.gov.br/. Acesso em: 17 ago. 2018.

OLIVEIRA, R. A. et al. Proposição de corredor ecológico entre duas unidades de conservação na região metropolitana de Sorocaba. Revista do Departamento de Geografia da USP, v. 32, p. 61-71, 2016.

OVIEDO, G. Áreas protegidas, desarrollo y cultura. Letras Verdes - Revista Latinoamericana de Estudios Socioambientales, n. 2, p. 1-4, 2013.

PELIZZARO, P. C. et al. Gestão e manejo de áreas protegidas: contexto internacional. Revista Ambiente \& Sociedade, v. 18, n. 1, p. 21-40, 2015. 
PRADO, E. V. et al. Proposta de um programa de ética e compliance integrado com a gestão de pessoas. Revista Perspectivas Contemporâneas, v. 13, n. 2, p. 1-23, 2018.

RIBAS, R. P.; GONTIJO, B. M. Mapeamento dos limites oficiais do mosaico de áreas protegidas do Espinhaço: interatividade entre o geoprocessamento e a gestão integrada do território. Revista Brasileira de Cartografia, v. 67, Edição Especial, p. 1.641-1.650, 2015.

RIONDET-COSTA, D. R. T. et al. Análise da participação social em conselhos de unidades de conservação em países da América do Sul. Revista Gestão \& Sustentabilidade Ambiental, v. 7, n. 4, p. 66-87, 2018.

RYLANDS, A. B.; BRANDON, K. Unidades de conservação brasileiras. Megadiversidade, v. 1, n. 1, p. 27-35, 2005.

SANCHÉZ, L. E. Por que não avança a avaliação ambiental no Brasil? Estudos Avançados, v. 32, n. 89, p. 167-183, 2017.

SILVA, J. I. A. O. As unidades de conservação, conforme a Lei № 9.985/2000: suas características e regime jurídico-ambientais. Revista Direito e Liberdade, v. 8, n. 1, p. 309-334, 2008.

SILVA, M. S. F.; SOUZA, R. M. Unidades de conservação como estratégia de gestão territorial dos recursos naturais. Revista TerraPlur@l, v. 3, n. 2, p. 241-259, 2009.

SILVA, T. A. Indicadores de sustentabilidade para o turismo: uma proposta para o Parque Estadual Marinho de Areia Vermelha - Pemav - Paraíba. 2016. Dissertação (Mestrado) - Universidade Federal da Paraíba, UFPB, João Pessoa, PB, 2016.

SKAFF. F. F.; TUPIASSU, L. V. C. Tributação e políticas públicas: o ICMS ecológico. Verba Juris, v. 3, n. 3, p. 154-190, 2004.

SMITH, W. S.; RIBEIRO, C. A. Parque Natural Municipal Corredores de Biodiversidade: pesquisas e perspectivas futuras. Sorocaba: Prefeitura; Secretaria do Meio Ambiente, 2015.

SUDEMA. Superintendência de Administração do Meio Ambiente do Estado da Paraíba. João Pessoa. 2018. Disponível em: http://sudema.pb.gov.br/unidades-de-conservacao-1. Acesso em: 14 fev. 2018.

SZKLAROWSKY, J. F. Lei 9.985, 2000 - SNUC - Sistemas de Unidades de Conservação da Natureza. Revista Busca Legis, n. 1, p. 1-13, 2001.

VALLEJO, L. R. Unidades de conservação: uma discussão teórica à luz dos conceitos de território e políticas públicas. Geographia, v. 4, n. 8, 2002.

WORLD BANK. Global environment benefits index for biodiversity. Disponível em: https://databank.worldbank.org/reports.aspx?source=1277\&series=ER.BDV.TOTL.XQ. Acesso em: 29 jan. 2020. 


\section{ANEXO 1}

\section{Governo do Estado da Paraibe}

Secretaria de Estado dos Recursos Hidricos, do Meio Ambiente e da Ciência c Tecnologia Superintendência de Administraçẩo do Meio Ambiente

OFÍCOO-CIRCULAR No 184 /2018/CEA/SUDEMA

João Pessoa, 18 de julho de 2018.

Ao Senho:

Thiago Silva

Doutorando em Mobilidade - Universidade de Coimbra

Programa de Pós-graduaçăo em desenvolvimento e meio ambiente.

Prezado Thiago,

A Coordenadoria de Estudos Ambientais (CEA), da Superintendéncia de Administração do Meio Ambiente (SUDEMA), recebeu a demanda protocolada com o $n^{*} 3078$ para responder ao email pedindo informaçăo sobre as UC's da Paraiba.

Informamos que a PB conta com 39 Unidades atuais sendo, 6 de competéncia federal, 15 estaduais, 7 municipais e 11 particulares e possivelmente trés futuras que será uma de competéncia federal e duas estaduais, em arquivo enviaremos os decretos de criaçăo $e$ as tabelas com informações de cada Unidade geridas pela Sudema.

Desde ja agradecemos e nos colocamos a disposição, para maiores esclarecimentos, através dos seguintes contatos: (83) 3221-6161, por oficio ou pelo e-mail (ceasudemapb@gmail.com].

Atenciosamente,
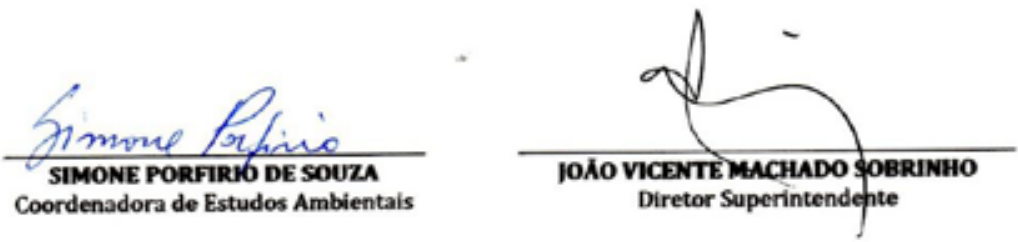

Av. Monsenhor Walfredo Leal, 181 - Tambia - João Pessoa - PB - CEP 58.020-540

Fones: (83) 3218-5602/3218-5581 FAX (83) 3218-5580

CGC 08.329.849/0001-15 email sudema $a$ sudema.ph,gov. br 